\title{
Perancangan Validasi Permohonan Narasumber Pada Sistem Informasi Permohonan Narasumber Menggunakan Finite State Automata
}

\author{
Fadillah Said $^{1}$, Dwi Andriyanto ${ }^{2}$, Retno Sari ${ }^{3}$, Windu Gata ${ }^{4}$ \\ ${ }^{1}$ STMIK Nusa Mandiri \\ e-mail: 14002413@nusamandiri.ac.id \\ ${ }^{2}$ STMIK Nusa Mandiri \\ e-mail: 14002432@nusamandiri.ac.id \\ ${ }^{3}$ STMIK Nusa Mandiri \\ e-mail: retno.rnr@nusamandiri.ac.id \\ ${ }^{4}$ STMIK Nusa Mandiri \\ e-mail: windu@nusamandiri.ac.id
}

\begin{abstract}
Intisari - Badan Penelitian dan Pengembangan Hukum dan Hak Asasi Manusia dalam melaksanakan tugas dan fungsinya memberikan pelayanan berupa layanan Penyediaan Narasumber. Pengelolaan surat secara manual membutuhkan waktu yang lama dan memungkinkan terjadinya kehilangan dokumen. Penelitian ini bertujuan untuk dapat mengurangi penggunaan waktu, membantu memperkecil terjadinya kehilangan surat, serta mengurangi kesalahan dalam pencatatan surat dengan menyimpannya pada basis data sesuai format yang ditentukan. Dalam rancang bangun sistem akan melakukan pengecekan input pemohon dan melakukan validasi sebelum data disimpan ke dalam basis data menggunakan Finite State Automata (FSA) agar data yang tersimpan sesuai dengan format yang ditentukan. Dengan diterapkannya penelitian ini diharapkan dapat membantu Badan Penelitian dan Pengembangan Hukum dan Hak Asasi Manusia untuk mengurangi penggunaan waktu, membantu memperkecil terjadinya kehilangan surat, serta mengurangi kesalahan dalam pencatatan surat sesuai dengan format yang ditentukan.
\end{abstract}

Kata Kunci: Sistem Informasi, Validasi, Finite State Automata, Surat Permohonan Narasumber

\begin{abstract}
The Law and Human Rights Research and Development Agency in carrying out its duties and functions provides services in the form of Providing Resource persons. Managing mail manually requires a long time and allows for document loss. This study aims to reduce the use of time, help minimize the loss of letters, and reduce errors in recording letters by storing them in a database in accordance with the specified format. In the design of the system will check the applicant's input and validate before the data is stored in the database using Finite State Automata (FSA) so that the data stored in accordance with the format specified. The implementation of this research is expected to be able to help the Law and Human Rights Research and Development Agency to reduce the use of time, help minimize the loss of letters, and reduce errors in recording letters in accordance with the specified format.
\end{abstract}

Key Word: Information System, Validation, Finite State Automata, Application Letter for Speaker

\section{PENDAHULUAN}

Badan Penelitian dan Pengembangan Hukum dan Hak Asasi Manusia (Balitbangkumham) merupakan unit organisasi yang berada dibawah dan bertanggung jawab kepada Menteri Hukum dan Hak Asasi Manusia yang mempunyai tugas untuk melakukan kegiatan penelitian dan pengembangan di bidang Hukum dan Hak Asasi Manusia. Adapun dalam melaksanakan tugas dan fungsinya Badan Penelitian dan Pengembangan Hukum dan Hak Asasi Manusia memberikan pelayanan berupa layanan Penyediaan Narasumber.
Narasumber/informan adalah seorang yang berperan dalam pengambilan data yang akan digali dan menguasai persoalan yang ingin diteliti dan berwawasan cukup (B. Oczalina, M. Ali, D. Miranda., 2019). Sebuah instansi, untuk bisa mendapatkan pelayanan penyediaan narasumber harus menyampaikan surat resmi berupa surat permohonan/permintaan narasumber yang kemudian dicatat kedalam buku surat masuk dan diteruskan kepada pimpinan untuk mendapatkan disposisi penunjukan narasumber.

Surat adalah sarana komunikasi untuk menyampaikan informasi tertulis oleh suatu pihak kepada pihak lain dan juga berfungsi sebagai alat 
pengingat yang dapat digolongkan menjadi tiga jenis, yaitu surat rahasia, surat penting, dan surat biasa (M. Junus, 2018) (H. N. Rosalia \& Alamsyah, 2017).

Pengelolaan surat dan tata persuratan yang merupakan bagian kecil dari kegiatan administrasi haruslah dilakukan dengan tepat dan sesuai dengan alur pelaksanaan serta haruslah ditata dan diarsipkan dengan baik karena akan mendukung tugas-tugas pimpinan, membantu merumuskan kebijaksanaan dan tujuan organisasi atau proses yang memberikan pengawasan pada semua hal yang terlibat dalam pelaksanaan kebijaksanaan dan pencapaian tujuan (H. N. Rosalia \& Alamsyah, 2017) (Ermawaty, 2013) (W. Pamulasari \& N. Suryana, 2020).

Masalah utama dalam pengelolaan surat permohonan narasumber secara manual adalah banyaknya jenis surat yang masuk membuat dalam proses pengelolaannya harus memilah antara surat masuk lainnya dengan surat permohonan/permintaan narasumber. Selain itu banyaknya aliran dokumen fisik yang dilakukan banyak menghabiskan waktu serta memungkinkan terjadinya kehilangan dokumen. Oleh karena itu diperlukan adanya sebuah sistem aplikasi yang diharapkan dapat membantu Balitbangkumham dapat mengurangi penggunaan waktu, membantu memperkecil terjadinya kehilangan surat serta mengurangi kesalahan dalam pencatatan surat dengan menyimpannya pada basis data sesuai format yang ditentukan.

Dalam penelitian ini dibuat rancangan sebuah sistem yang dapat mengolah surat permohonan/ permintaan narasumber. Dalam mengajukan surat permohonan, pemohon mengisi input berupa Nama Instansi, Nama Satuan Kerja, Nomor Surat, Tangal Surat, Kategori Surat, Nama Acara, Latar Belakang, Tujuan, Tanggal dan Waktu Mulai Acara, Tanggal dan Waktu Selesai Acara, Tempat Pelaksanaan, Peserta, Nama Kontak, Nomor Kontak, Email dan File Surat Permohonan. Agar data tersebut sesuai dengan kebutuhan penyimpanan ke dalam basis data maka sistem akan melakukan pengecekan input dan melakukan validasi sebelum data disimpan ke dalam basis data menggunakan Finite State Automata (FSA) agar data yang tersimpan sesuai dengan format yang ditentukan.

Sistem dapat didefinisikan sebagai sebuah kesatuan yang terdiri atas objek-objek atau unsur-unsur yang berkaitan atau berhubungan satu sama lainnya yang merupakan suatu kesatuan pemrosesan atau pengolahan dari dua atau lebih subsistem dan dapat didefinisikan menurut dua kelompok pendekatan, yaitu pada prosedurnya dan pada komponen atau elemen yang berinteraksi guna mencapai suatu tujuan (W. Pamulasari \& N. Suryana, 2020) (N. Suarna, S. Anwar, N. Rahaningsih. 2019).
Informasi adalah data yang telah diolah untuk digunakan dalam proses pengambilan keputusan (Andoyo, R. Rianto, 2015). Salah satu contoh bentuk sistem adalah sistem informasi berbasis web. Sistem informasi berbasis web merupakan sebuah sistem di dalam suatu organisasi yang dapat digunakan untuk kebutuhan penyebaran informasi melalui layanan internet yang mendukung fungsi operasi organisasi (H. Basri, S. Alfarizi, A. R. Mulyawan, A. Wiguna \& I. Habiba, 2019).

Otomata adalah mesin yang dapat mengenali, menerima, atau membangkitkan kalimat dalam bahasa tertentu. Otomata menerima input dan menghasilkan output. Input dianggap sebagai bahasa yang harus dikenali oleh mesin yang selanjutnya membuat keputusan apakah input diterima atau tidak. String input diterima bila mencapai state akhir/ final state, dan sebaliknya (Widyasari, 2011).

FSA adalah mesin otomata dalam bentuk model matematika yang memiliki sejumlah state (kedudukan) tak berhingga banyaknya dan dapat berpindah dari suatu state ke state lain dengan fungsi transisi. Berdasarkan definisi kemampuan berubah statenya, FSA bisa dikelompokkan:

1. Otomata berhingga deterministik (Deterministik Finite Automata/DFA)

2. Otomata berhingga non deterministik (Non Deterministik Finite Automata/NFA/NDFA) (S. Suparyanto. 2017).

DFA menggambarkan suatu keadaan dengan menghantarkan satu input kesetiap state yang ada (K. Handoko \& A. W. Aranski, 2019). NFA merupakan jenis finite state machine (FSM) dimana next state tidak sepenuhnya ditentukan oleh current state ataupun input. Automata dapat berpindah dari state tertentu ke state yang lain sebagai tanggapan terhadap suatu input (Sahrul, F. Karimah, A. Muhazabah, A. D. Prasetyo, A. Yunita \& N. L. Zahra, 2018). NFA dan DFA adalah jenis utama yang digunakan pada berbagai tingkat pemodelan dan spesifikasi (G. V. Saragih, A. Faisal \& W. Gata, 2020).

FSA dinyatakan dalam 5 (lima) tupel atau $\mathrm{M}=(\mathrm{Q}$, $\left.\sum, \delta, \mathrm{S}, \mathrm{F}\right)$ dimana:

$\mathrm{Q}=$ himpunan state/ kedudukan

$\sum=$ himpunan simbol input/ masukan/ abjad

$\delta=$ fungsi transisi

$\mathrm{S}=$ state awal (initial state), $\mathrm{S} \in \mathrm{Q}$

$\mathrm{F}=$ himpunan state akhir, $\mathrm{F} \cap \mathrm{Q}$ (jumlah state akhir dalam suatu FSA bisa lebih dari satu)

Simbol merupakan sebuah entitas abstrak (seperti halnya titik dalam geometri). Huruf atau angka merupakan contoh dari simbol, sedangkan string merupakan deretan terbatas (finite) simbol-simbol (S. Suparyanto. 2017). Sebagai contoh apabila x, y, dan $\mathrm{z}$ merupakan tiga buah simbol, maka xyzy 
adalah string yang dibentuk dari ketiga simbol tersebut. Alfabet merupakan himpunan hingga (finite set) dari simbol-simbol (S. Suparyanto. 2017).

Pada penelitian sebelumnya sudah banyak penelitian tentang penerapan atau penggunaan FSA. Penelitian pertama yang berjudul "Telaah Teoritis Finite State Automata Dengan Pengujian Hasil Pada Mesin Otomata" pada penelitian ini membahas tentang teori Bahasa dan otomata yang merupakan Langkah awal dan gagasan untuk menghasilkan Teknik rekayasa dalam perancangan perangkat keras maupun perangkat lunak.

Penelitian kedua yang berjudul "Simulator Pengenal String Yang Diterima Sebuah Deterministic Finite Automata (DFA)" pada penelitian ini membahas tentang Simulator DFA sebagai sebuah perangkat yang bisa dipergunakan untuk melakukan pengecekan terhadap input string pada DFA sebelum sebuah string di inputkan kedalam sebuah DFA.

Penelitian ketiga yang berjudul "Rancangan Pemilihan Paket Pelaminan Menggunakan Finite State Automata di Kota Batam" pada penelitian ini membahas tentang cara atau diagram yang bisa digunakan untuk membuat keputusan yang simpel dalam pengambilan keputusan terhadap pemilihan paket pelaminan menggunakan FSA.

Penelitian keempat yang berjudul "Pengembangan Aplikasi Permainan "Pilah Sampah" Menggunakan Pemodelan Finite State Machine" pada penelitian ini membahas tentang bagaimana FSM dapat diaplikasikan untuk mendesain aplikasi permainan bernama Pilah Sampah sebagai diagram model bisnis.

Penelitian kelima yang berjudul "Desain Vending Machine Rokok Dengan Mengimplementasikan Finite State Automata Terintegrasi Dengan E-KTP" pada penelitian ini membahas tentang desain mesin penjualan rokok otomatis atau vending machine yang terintegrasi dengan database e-KTP untuk mengambil data usia pembeli.

Penelitian keenam yang berjudul "Verifying ClientSide Input Validation Functions Using String Analysis" pada penelitian ini membahas tentang penggunaan DFA untuk memverifikasi fungsi validasi input pada sisi klien menggunakan analisis string.

Penelitian ketujuh yang berjudul "String Analysis for Vulnerability Detection and Repair" penelitian ini membahas tentang Analisis string untuk mendeteksi dan memperbaiki sebuah vulnerability berdasarkan analisis string berbasis automata.

Penelitian kedelapan yang berjudul "Practical Programming, Validation and Verification with
Finite-State Machines: a Library and its Industrial Application" penelitian ini membahas tentang penyediaan sebuah library bernama Verum yang memungkinkan spesiasi, eksekusi, dan verifikasi FSM dalam bahasa ruby yang secara eksplisit untuk memotong kebutuhan penggunaan bahasa pemodelan tambahan.

Penelitian kesembilan yang berjudul "Implementasi Finite State Automata dalam Proses Pengisian Kartu Rencana Studi Mahasiswa" penelitian ini membahas tentang implementasi FSA dalam mengisi kartu rencana studi mahasiswa (KRS).

Penelitian kesepuluh yang berjudul "Identifikasi File JPEG dengan Metode Signature Based Carving dalam Model Automata" penelitian ini membahas tentang proses identifikasi dan recovery file JPEG dengan metode Signature-Based Carving, dengan sebuah model diagram FSA.

Basis data adalah kumpulan data yang dihubungkan bersama-sama yang dirancang untuk memenuhi kebutuhan informasi suatu organisasi yang menyimpan data secara terintegrasi dan dapat digunakan bersama (S. Khotijah, 2016).

Masalah terpenting dalam mengembangkan aplikasi web yang dapat diandalkan adalah kebenaran operasi validasi input. Salah satu bentuk interaksi utama antara pengguna dan aplikasi web adalah melalui kolom input teks, di mana pengguna mengetik teks sebagai input yang kemudian diuraikan oleh aplikasi web dan dikonversi ke beberapa tipe data tertentu seperti tanggal, nomor kartu kredit, atau alamat email. Aplikasi web perlu memisahkan input pengguna yang valid dar input yang tidak cocok dengan jenis input yang diharapkan dan meminta pengguna untuk memasukan kembali input yang sesuai jika perlu (M. Alkhalaf, T. Bultan \& J. L. Gallegos, 2012).

Ekstraksi otomatis dalam operasi validasi dan sanitasi yang diberikan dari aplikasi web, mencegah jika ada kerentanan dengan secara otomatis menganalisis operasi string yang diekstraksi, dan secara otomatis menghasilkan perbaikan yang menghilangkan kerentanan yang diidentifikasi ( $\mathrm{T}$. Bultan, 2015).

FSM memungkinkan programmer untuk mengambil manfaat dari kesederhanaan mereka, tetapi tidak memberikan dukungan langsung untuk verifikasi formal mereka atau bahkan jenis analisis yang lebih sederhana (P. Salem, 2016).

Prefiksensi merupakan hal mendasar dalam teori pengkodean; misalnya, kode Huffman adalah set Prefix-free. Keuntungan kode Prefix-free adalah kita dapat mendekodekan string yang dikodekan secara deterministik. Karena kode adalah bahasa dan kode 
Prefix-free adalah subfamili kode yang tepat, bahasa reguler Prefix-free adalah subfamili kode bahasa biasa. Bahasa Prefix-free reguler telah digunakan untuk menentukan determinisme untuk automata umum dan untuk automata ekspresi (Y-S. Han, Y. Wang \& D. Wood, 2007).

Reguler Expressions (RegEx) menyediakan sarana untuk mencocokkan dan mengekstraksi data yang melampaui pencocokan pola biasa seperti yang ditemukan dan telah terbukti bermanfaat untuk manipulasi string dan untuk diproses data terstruktur seperti XML (N. Broberg, A. Farre, J. Svenningsson, 2004).

Pencocokan RegEx saat ini biasanya menerjemahkan seluruh RegEx menjadi sebuah finite automata (FA). Jika jumlah state dari DFA menjadi terlalu besar, maka harus menggunakan sebuah NFA yang lebih lambat untuk pencocokan seluruh $\operatorname{RegEx}$ (X. Wang, Y. Hong, H. Chang, K. Park, G. Langdale, J. Hu \& H. Zhu, 2019).

Berdasarkan permasalahan yang ada maka penelitian ini bertujuan untuk melakukan Perancangan Validasi Permohonan Narasumber pada Sistem Informasi Permohonan Narasumber sebagai sebuah sistem aplikasi yang diharapkan dapat membantu Balitbangkumham dapat mengurangi penggunaan waktu, membantu memperkecil terjadinya kehilangan surat, serta mengurangi kesalahan dalam pencatatan surat sesuai dengan format yang ditentukan.

\section{METODE PENELITIAN}

Tahapan Penelitian yang digunakan dalam penelitian ini dapat dibagi ke dalam 4 (empat) tahap yaitu: (1) Identifikasi Masalah, (2) Perancangan Finite State Automata, (3) Perancangan Sistem Informasi Permohonan Narasumber, (4) Design Sistem Informasi Permohonan Narasumber.

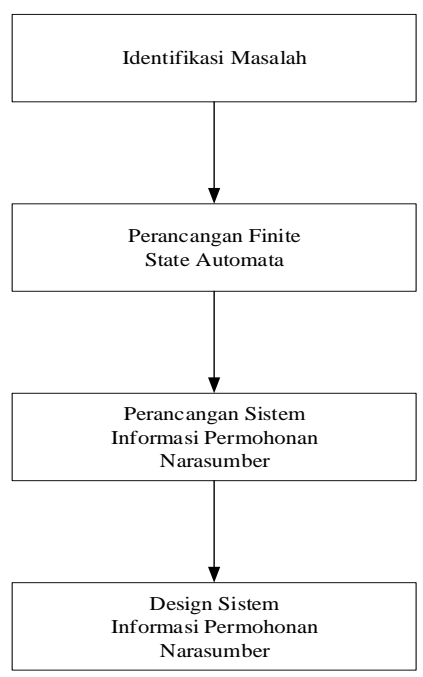

Gambar 1. Tahapan Penelitian
Pada Gambar 1 menjelaskan tahapan penelitian yang digunakan dalam penelitian ini, sebagai berikut:

1. Tahap Identifikasi Masalah Pada tahap ini dilakukan proses deteksi atas permasalahan-permasalahan yang ada.

2. Tahap Perancangan FSA Pada tahap ini akan dilakukan perancangan FSA menggunakan NFA.

3. Tahap Perancangan Sistem Informasi Permohonan Narasumber

Pada tahap ini dilakukan perancangan Sistem Informasi Permohonan Narasumber menggunakan Unified Modelling Language (UML).

4. Tahap Design Sistem Informasi Permohonan Narasumber

Pada tahap ini dilakukan design tampilan antarmuka Sistem Informasi Permohonan Narasumber.

\section{HASIL DAN PEMBAHASAN}

\section{Perancangan FSA}

Perancangan FSA menggunakan NFA yang akan dibangun dijelaskan pada gambar sebagai berikut:

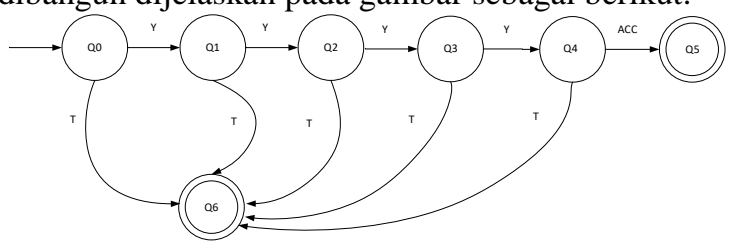

Gambar 2. Diagram state NFA pengajuan permohonan narasumber

Gambar 2 menunjukan rancangan diagram state yang menjelaskan alur Sistem Informasi Permohonan Narasumber. Secara formal FSA pada Gambar 2 dinyatakan dalam 5 (lima) tuple sebagai berikut:

$\sum=\{\mathrm{Y}, \mathrm{N}, \mathrm{ACC}\}$

$\square \quad=$ Fungsi transisi untuk pengajuan permohonan

(Tabel 3)

$\mathrm{Q}=\{\mathrm{Q} 0, \mathrm{Q} 1, \mathrm{Q} 2, \mathrm{Q} 3, \mathrm{Q} 4\}$

$\mathrm{S}=\{\mathrm{Q} 0\}$

$\mathrm{F}=\{\mathrm{Q} 4\}$

Tabel 1. Himpunan state

\begin{tabular}{|c|l|}
\hline State & \multicolumn{1}{|c|}{ Deskripsi } \\
\hline Q0 & $\begin{array}{l}\text { Pengisian Form, adalah start state, dimana } \\
\text { merupakan titik awal pemohon melakukan } \\
\text { pengajuan permohonan }\end{array}$ \\
\hline Q1 & Nomor telephone \\
\hline Q2 & Email \\
\hline Q3 & Tipe file \\
\hline Q4 & Size file \\
\hline Q5 & $\begin{array}{l}\text { Nomor token, adalah final state, dimana } \\
\text { nomor token merupakan tujuan akhir ketika } \\
\text { form diterima }\end{array}$ \\
\hline Q6 & Tidak diterima \\
\hline
\end{tabular}


Tabel 1 memberikan penjelasan tentang himpunan state yang ada pada diagram perancangan FSA.

Tabel 2. Himpunan abjad

\begin{tabular}{|c|l|l|}
\hline Abjad & \multicolumn{3}{|c|}{ Deskripsi } \\
\hline $\mathrm{Y}$ & $\begin{array}{l}\mathrm{Y} \text { adalah inisial Ya untuk ke state } \\
\text { berikutnya }\end{array}$ \\
\hline $\mathrm{T}$ & $\begin{array}{l}\mathrm{T} \text { adalah inisial Tidak untuk ke state } \\
\text { berikutnya }\end{array}$ \\
\hline ACC & ACC adalah inisial accept \\
\hline
\end{tabular}

Tabel 2 memberikan penjelasan tentang himpunan abjad yang ada pada diagram perancangan FSA.

Tabel 3. Relasi transisi

\begin{tabular}{|c|c|c|c|}
\hline$\square$ & $\mathrm{Y}$ & $\mathrm{T}$ & $\mathrm{ACC}$ \\
\hline $\mathrm{Q}$ 0 & Q1 & Q6 & $\varnothing$ \\
\hline Q1 & Q2 & Q6 & $\varnothing$ \\
\hline Q2 & Q3 & Q6 & $\varnothing$ \\
\hline Q3 & Q4 & Q6 & $\varnothing$ \\
\hline Q4 & $\varnothing$ & Q6 & Q5 \\
\hline Q5 & $\varnothing$ & $\varnothing$ & $\varnothing$ \\
\hline
\end{tabular}

Tabel 3 menjelaskan tentang perpindahan state yang ada pada diagram perancangan FSA apabila ada input yang masuk. Sebagai contoh state Q0 mendapatkan input yang lengkap maka akan berpindah ke state Q1, namun apabila mendapat input yang tidak lengkap maka akan berpindah ke state Q6. Perpindahan antar state tersebut akan bernilai $\mathrm{T}$ jika input yang masuk tidak sesuai.

Setelah rancangan NFA selesai dibuat, tahap selanjutnya adalah mengaplikasikan rancangan agar dapat dengan mudah digunakan dan diterapkan pada rancangan sistem agar proses pembuatannya dapat diselesaikan dengan mudah.

\section{Perancangan Sistem Informasi}

Unifed Modeling language (UML) merupakan kumpulan diagram-diagram yang sudah memiliki standar untuk membangun perangkat lunak berbasis objek [24].

\section{a. Use Case Pengisian Form Permohonan}

Narasumber

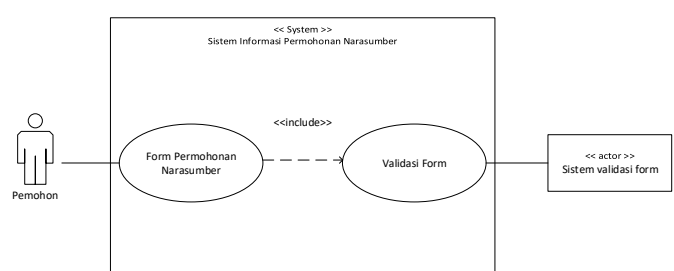

Gambar 3. Use Case Pengisian Form Permohonan Narasumber

Pada Gambar 3 menjelaskan Sistem Informasi Permohonan Narasumber mempunyai 2 (dua) actor yaitu actor Pemohon yang bisa mengajukan permohonan narasumber. Kemudian actor Sistem validasi form yang akan melakukan validasi terhadap pengisian form permohonan narasumber.

b. Activity Diagram Pengisian Form Permohonan Narasumber

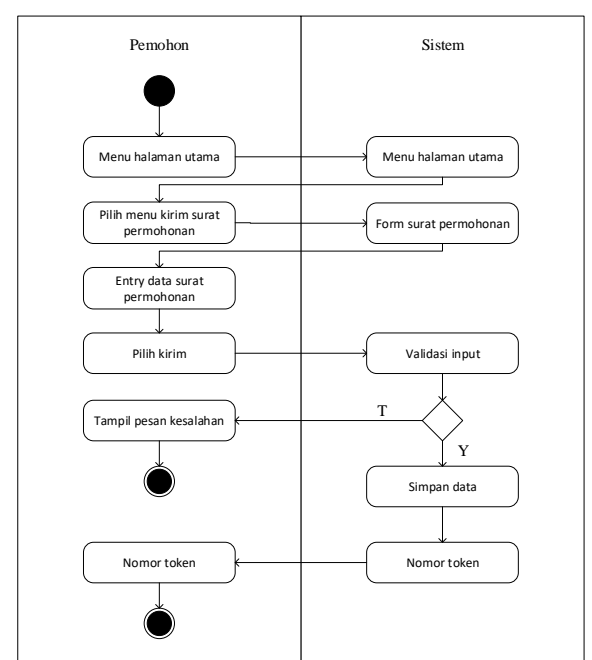

Gambar 4. Activity Diagram Pengisian Form Permohonan Narasumber

Pada Gambar 4 menjelaskan pemohon mengakses halaman utama sistem, setelah itu pemohon memilih menu kirim surat permohonan. Sistem kemudian akan menampilkan form surat permohonan. Pemohon mengentry data surat permohonan kemudian memilih tombol kirim. Sistem akan melakukan validasi data yang diinput, jika tidak sesuai dengan format yang ditentukan maka sistem akan menampilkan pesan kesalahan. Jika sesuai dengan format yang ditentukan maka sistem akan menyimpan data surat permohonan kemudian menampilkan nomor token kepada pemohon.

\section{Design Sistem Informasi}

Sistem Informasi Permohonan Narasumber memiliki tampilan antarmuka sebagai berikut:

a. Halaman utama

Halaman utama adalah halaman yang akan tampil ketika pengunjung web membuka web Sistem Informasi Permohonan Narasumber

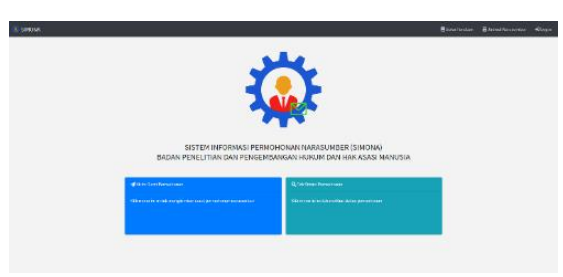

Gambar 5. Halaman utama

b. Form Permohonan Narasumber

Digunakan oleh pemohon untuk mengajukan permohonan narasumber. 


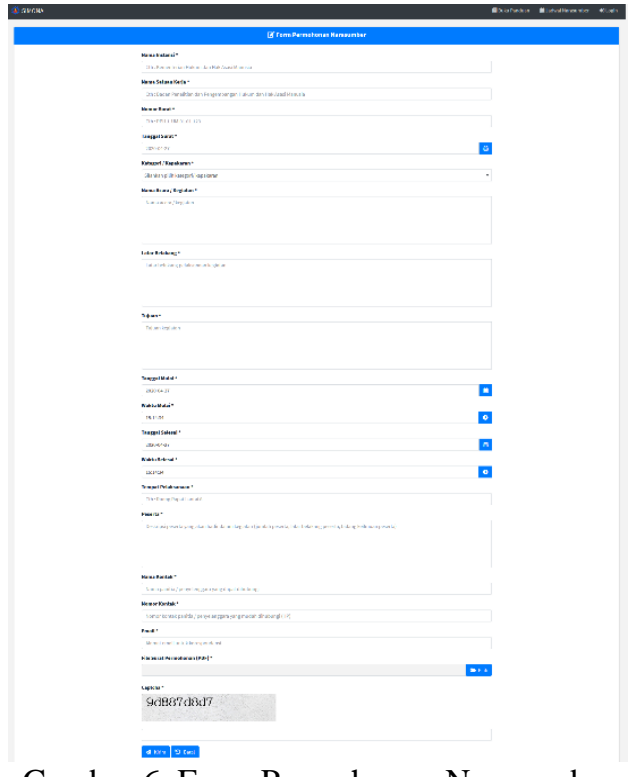

Gambar 6. Form Permohonan Narasumber

c. Tampilan pesan kesalahan jika form belum dilengkapi

Pesan yang akan tampil jika pemohon belum melengkapi pengisian form

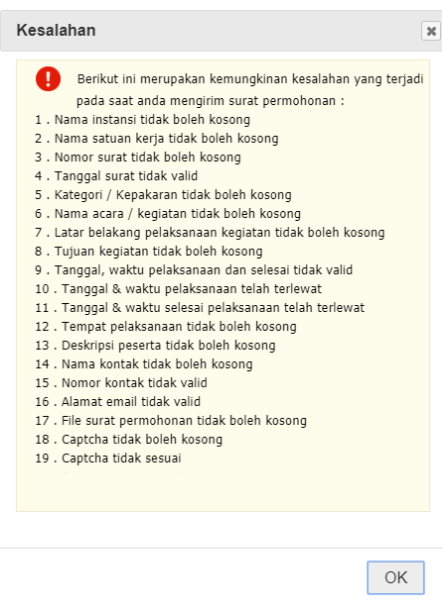

Gambar 7. Pesan kesalahan jika form belum dilengkapi

d. Tampilan pesan kesalahan jika mandatory field belum diisi

Pesan yang akan tampil jika mandatory field belum diisi oleh pemohon

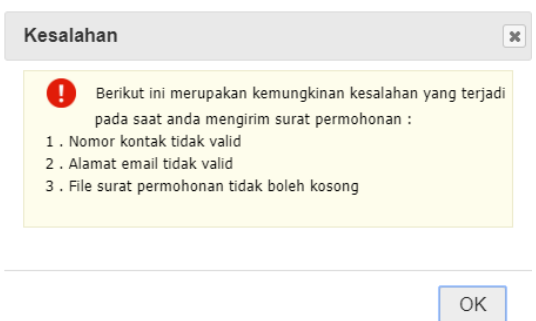

Gambar 8. Pesan kesalahan jika mandatory field belum diisi e. Tampilan pesan kesalahan jika nomor telephone tidak sesuai

Pesan yang akan tampil jika pemohon tidak mengisi nomor telephone dengan benar

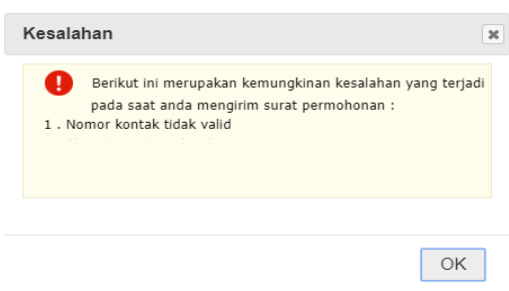

Gambar 9. Pesan kesalahan jika nomor telephone tidak sesuai

f. Tampilan pesan kesalahan jika email tidak sesuai

Pesan yang akan tampil jika pemohon tidak mengisi alamat email dengan benar

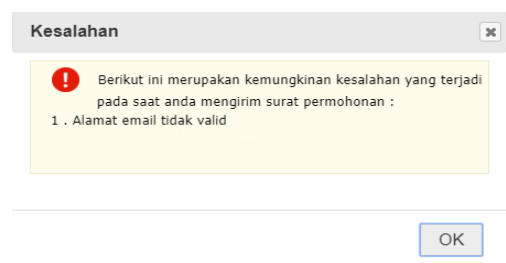

Gambar 10. Pesan kesalahan jika email tidak sesuai

g. Tampilan pesan kesalahan jika format file yang diunggah tidak sesuai

Pesan yang akan tampil jika pemohon tidak mengunggah file sesuai dengan format file yang ditentukan
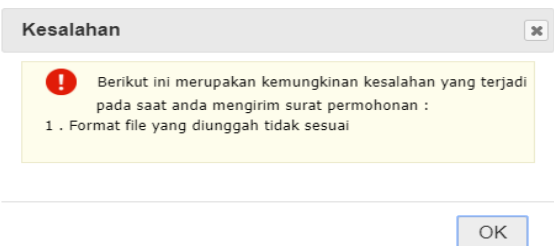

Gambar 11. Pesan kesalahan jika format file yang diunggah tidak sesuai

h. Tampilan pesan kesalahan jika ukuran file yang diunggah tidak sesuai

Pesan yang akan tampil jika pemohon tidak mengunggah file sesuai dengan ukuran file yang ditentukan

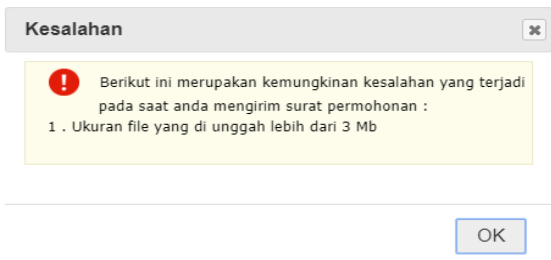

Gambar 12. Pesan kesalahan jika ukuran file yang diunggah tidak sesuai. 


\section{KESIMPULAN}

Berdasarkan hasil penelitian dan pembahasan yang dilakukan, dapat disimpulkan bahwa FSA dapat digunakan sebagai logika dasar dalam proses validasi permohonan narasumber pada sistem informasi permohonan narasumber. Adapun kondisi yang harus dipenuhi dalam proses validasi adalah nomor telephone, email, tipe dan ukuran file. Dengan diterapkannya penelitian ini diharapkan dapat membantu Balitbangkumham untuk mengurangi penggunaan waktu, membantu memperkecil terjadinya kehilangan surat, serta mengurangi kesalahan dalam pencatatan surat sesuai dengan format yang ditentukan setelah terlebih dahulu dilakukan validasi oleh sistem.

\section{REFERENSI}

A. Andoyo, R. Rianto. (2015). Program Aplikasi Nilai Siswa Pada SMK Muhammadiyah Pringsewu Sebagai Penunjang Pengambilan Keputusan Siswa Berprestasi Menggunakan Visual Basic 6.0. Jurnal TAM (Technology Acceptance Model), Vol. 5.

Ardiansyah, N. Hardi, W. Gata. (2020). Identifikasi File JPEG dengan Metode Signature Based Carving dalam Model Automata. Komputika: Jurnal Sistem Komputer Volume 9, Nomor 1, April 2020, hlm. 75 - 83.

B. Oczalina, M. Ali, D. Miranda. (2019). Pemanfaatan Lingkungan Sebagai Media Belajar Dalam Pembelajaran di TK Negeri Pembina Pontianak Selatan. Jurnal Pendidikan dan Pembelajaran Khatulistiwa, Vol. 8, No. 1.

Ermawaty. (2013). PENGELOLAAN SURAT DAN TATA PERSURATAN DALAM ARSIP. Pelangi Pendidikan, Vol. 20 No. 1 Juni 2013.

F. Ayu, N. Permatasari. (2018). PERANCANGAN SISTEM INFORMASI PENGOLAHAN DATA PRAKTEK KERJA LAPANGAN (PKL) PADA DEVISI HUMAS PT. PEGADAIAN. Jurnal Intra-Tech Volume 2, No.2 Oktober 2018.

G. V. Saragih, A. Faisal, W. Gata. (2020). Desain Vending Machine Rokok Dengan Mengimplementasikan Finite State Automata Terintegrasi Dengan E-KTP. MATICS : Jurnal Ilmu Komputer dan Teknologi Informasi Volume 12, No. 1, Maret 2020, pp 55-60.
H. Basri, S. Alfarizi, A. R. Mulyawan, A. Wiguna, I. Habiba. (2019). PERANCANGAN SISTEM INFORMASI BOOKING PEREKAMAN EKTP (SI MBOK) BERBASIS WEB. Jurnal PILAR Nusa Mandiri Vol. 15, No. 1 Maret 2019

H. N. Rosalia, Alamsyah. (2017) ANALISIS PENERAPAN SISTEM PENGELOLAAN PERSURATAN DALAM KEGIATAN TEMU KEMBALI ARSIP SURAT DI PT PELINDO III (PERSERO) CABANG TANJUNG EMAS SEMARANG. Jurnal Ilmu Perpustakaan Vol 6, No 1 (2017): Januari 2017.

K. Handoko, A. W. Aranski. (2019). Rancangan Pemilihan Paket Pelaminan Menggunakan Finite State Automata di Kota Batam. SNISTEK 2, 31 Agustus - 1 September 2019.

M. Alkhalaf, T. Bultan, J. L. Gallegos. (2012). Verifying Client-Side Input Validation Functions Using String Analysis. In 34th International Conference on Software Engineering (ICSE). Zurich, Switzerland, 2012. IEEE. DOI: 10.1109/ICSE.2012.6227124.

M. Junus. (2018). SISTEM INFORMASI PENGELOLAAN SURAT MASUK \& SURAT KELUAR JURUSAN TEKNIK ELEKTRO POLITEKNIK NEGERI MALANG BERBASIS WEB MELALUI JARINGAN INTRANET POLINEMA. Jurnal ELTEK, Vol 16 Nomor 02, Oktober 2018.

N. Broberg, A. Farre, J. Svenningsson. (2004). Regular Expression Patterns. ACM SIGPLAN Notices Vol. 39, No. 9.

N. Suarna, S. Anwar, N. Rahaningsih. (2019). SISTEM INFORMASI MANAJEMEN PENGARSIPAN BERBASIS FRAMEWORK CODE IGNITER UNTUK MENTERTIBKAN PELAYANAN SURAT MENYURAT (STUDI KASUS : DINAS KEARSIPAN DAN PERPUSTAKAAN). Information System Journal (INTERNAL) Vol 2, No 1 (2019).

P. Salem. 2016. Practical Programming, Validation and Verification with Finite-State Machines: a Library and its Industrial Application. In 38th IEEE International Conference on Software Engineering Companion. ICSE '16 Companion, May 14-22, 2016, Austin, TX, USA. IEEE/ACM. DOI : $10.1145 / 2889160.2889226$. 
R. A. Ma'arif, Fauziah. (2018). Implementasi Finite State Automata dalam Proses Pengisian Kartu Rencana Studi Mahasiswa. (JOINTECS) Journal of Information Technology and Computer Science Vol. 3, No. 3, September 2018.

Sahrul, F. Karimah, A. Muhazabah, A. D. Prasetyo, A. Yunita, N. L. Zahra. (2018). PENGEMBANGAN APLIKASI PERMAINAN "PILAH SAMPAH" MENGGUNAKAN PEMODELAN FINITE STATE MACHINE. Jurnal Teknologia Aliansi Perguruan Tinggi (APERTI) BUMN Vol. 1, No. 1, Agustus 2018.

S. Khotijah. (2016). PERANCANGAN DATABASE E-LEARNING MANAJEMEN SYSTEM UNTUK PEMBELAJARAN PADA SEKOLAH MENENGAH PERTAMA. Jurnal String (Satuan Tulisan Riset dan Inovasi Teknologi) Vol. 1 No. 1 Tahun 2016.

S. Suparyanto. (2017). Simulator Pengenal String Yang Diterima Sebuah Deterministic Finit Automata (DFA). 9th National Conference on Information Technology and Electrical Engineering (CITEE) 2017. Yogyakarta, 27 Juli 2017.

T. Bultan. (2015). String Analysis for Vulnerability Detection and Repair. In 22 International Symposium, Spin 2015. Stellenbosch, South Africa, August 24-26, 2015 Proceedings. Springer. DOI : 10.1007/978-3-319-23404-5.

Widyasari. (2011). Telaah Teoritis Finite State Automata Dengan Pengujian Hasil Pada Mesin Otomata. Jurnal Ilmiah SISFOTENIKA Vol. 1, No. 1, Januari 2011.

W. Pamulasari, N. Suryana. (2020). RANCANG BANGUN SISTEM INFORMASI MANAJEMEN SURAT BERBASIS WEB PADA KANTOR BPJS KETENAGAKERJAAN CABANG SUKABUMI. ENSAINS: Vol. 3 Nomor. 1 Januari 2020.
X. Wang, Y. Hong, H. Chang, K. Park, G. Langdale, J. Hu, H. Zhu. 2019. Hyperscan: A Fast Multi-pattern Regex Matcher for Modern CPUs. Proceedings of the 16th USENIX Symposium on Networked Systems Design and Implementation, NSDI 2019 (2019) 631648.

Y-S. Han, Y. Wang, D. Wood. 2007. Prefix-free regular languages and pattern matching. Theoretical Computer Science. Volume 389, Issues 1-2, 10 December 2007, Pages 307317.

\section{PROFIL PENULIS}

Fadillah Said, S.Kom. Tahun 2010 lulus dari Program Strata Satu (S1) Program Studi Sistem Informasi STMIK Nusa Mandiri Jakarta. Saat ini bekerja sebagai Pranata Komputer Ahli Pertama di Badan Penelitian dan Pengembangan Hukum dan Hak Asasi Manusia.

Dwi Andriyanto, S.Mn. Tahun 2008 lulus dari Program Strata Satu (S1) Program Studi Manajemen Universitas Terbuka. Saat ini bekerja sebagai Pranata Komputer Muda di Direktorat Jenderal Pajak, Direktorat Teknologi Informasi dan Keuangan (TIK)

Retno Sari, S.Kom., M.Kom. Tahun 2011 lulus dari Program Strata Satu (S1) Program Studi Sistem Informasi STMIK Nusa Mandiri Jakarta. Tahun 2015 lulus dari Program Pascasarjana (S2) Program Studi Magister Ilmu Komputer STMIK Nusa Mandiri Jakarta. Saat ini bekerja sebagai tenaga pengajar di STMIK Nusa Mandiri Jakarta.

Dr. Windu Gata, S.Kom., M.Kom. Tahun 1999 lulus dari Program Strata Satu (S1) Universitas Budi Luhur. Tahun 2008 lulus dari Program Pascasarjana (S2) Universitas Budi Luhur. Tahun 2015 lulus dari Program Doktoral (S3) Universitas Negeri Jakarta. Saat ini bekerja sebagai tenaga pengajar di STMIK Nusa Mandiri Jakarta. 